\title{
Agricultores familiares em canais curtos de comercialização: uma análise quantitativa das feiras municipais
}

\author{
Family farmers in short food supply chains: a quantitative assessment of \\ farmers' markets \\ Thiago de Carvalho Verano $^{1}$ (1), Reginaldo Santana Figueiredo ${ }^{1}$ (), Gabriel da Silva Medina² (1) \\ ${ }^{1}$ Universidade Federal de Goiás (UFG), Goiânia (GO), Brasil. E-mails: veranoseco@gmail.com; emaildesantana@gmail.com \\ ²Universidade de Brasília (UnB), Brasília (DF), Brasil. E-mail: gabriel.medina@unb.br
}

\begin{abstract}
Como citar: Verano, T. C., Figueiredo, R. S., \& Medina, G. S. (2021). Agricultores familiares em canais curtos de comercialização: uma análise quantitativa das feiras municipais. Revista de Economia e Sociologia Rural, 59(3), e228830. https://doi.org/10.1590/1806-9479.2021.228830
\end{abstract}

\begin{abstract}
Resumo: O potencial de inserção comercial de agricultores familiares em canais curtos de comercialização tem sido explorado por importantes estudos qualitativos. Este trabalho apresenta contribuições adicionais a esses esforços ao quantificar a participação de agricultores familiares nas feiras municipais. Verifica-se em que medida as feiras representam alternativas à inserção comercial ao proporcionar: (a) inclusão socioprodutiva dos agricultores familiares; (b) fortalecimento de canais curtos de comercialização; e (c) alternativa ao sistema agroalimentar industrial. A partir de dados quantitativos de 59 feiras, amostradas de um universo de 369 no estado de Goiás, detectou-se que 42,37\% das feiras oferecem oportunidades de inclusão comercial aos agricultores familiares, 32,20\% fortalecem canais curtos de comercialização e 35,59\% funcionam como alternativa ao sistema agroalimentar industrial. Do total, $10,17 \%$ das feiras atendem aos três critérios supracitados concomitantemente. As regressões estatísticas revelam que: (1) quanto menor a porcentagem de atravessadores e maior a de agricultores ligados a organizações, maior é a possibilidade de a feira ter mais bancas da agricultura familiar; (2) quanto maior a relevância da feira como espaço de articulação entre agentes e para a catalisação de novos negócios entre agricultores, maior a possibilidade desse canal exercer influência na criação ou no fortalecimento de políticas públicas.
\end{abstract}

Palavras-chave: desenvolvimento rural, comercialização, inclusão socioeconômica, feira do produtor.

\begin{abstract}
Qualitative research projects have revealed the importance of short food supply chains for providing alternatives for family farmers marketing their agricultural goods. This study presents an additional contribution to these efforts by quantifying the participation of family farmers in farmers' markets at the county level. It assesses to what extent farmers' markets represent an alternative market channel by providing: (a) opportunities for family farmers selling their goods; (b) functional short food supply chains and; (c) alternatives to the industrial supply chains. Based on quantitative data from 59 markets, sampled from a universe of 369 farmers' markets in the Brazilian State of Goiás, we found that $42.37 \%$ of the farmers' markets offer opportunities for family farmers, $32.20 \%$ promote local short marketing channels, and $35.59 \%$ work as an alternative to the industrial agri-food systems. As a whole, $10.17 \%$ of the studied farmers' markets meet the three above-mentioned objectives. Statistical regressions reveal that: 1) the lower the percentage of middlemen and the greater the percentage of family farmers taking part in farming organizations, the greater the number of stands owned by family farmers; 2) the greater the relevance of the farmers' market in both the organization of farmers and in the catalysis of new business, the greater the positive influence on public policies.
\end{abstract}

Keywords: rural development, commercialization, socio-economic inclusion, farmers' market. 


\section{INTRODUÇÃO}

Existe grande esforço acadêmico para analisar novos processos de produção, de distribuição e de alimentação ao redor do mundo que são alternativos às cadeias agroindustriais convencionais (Conterato et al., 2011). Estudos sobre cadeias curtas de comercialização avaliam o potencial de canais alternativos como vendas na propriedade, cestas de produtos, feiras do agricultor, bancas de beira de estradas, lojas especializadas e community supported agriculture (CSA) (Darolt et al., 2016). Esses trabalhos exploram um novo paradigma de desenvolvimento rural a partir de experiências empíricas exitosas de diálogo entre produtores rurais e consumidores.

No Brasil, também existe esforço acadêmico importante para compreender o papel das cadeias curtas de comercialização, em particular para os agricultores familiares (Wilkinson, 2003; Scarabelot \& Schneider, 2013). Apesar do surgimento de novas relações produçãoconsumo, nas quais os consumidores buscam produtos com características locais, cuidado com a paisagem e valorizam as tradições e os modos de vida dos agricultores, as feiras municipais ainda são o principal canal curto disponível para agricultores familiares brasileiros (Darolt et al., 2016). As feiras municipais podem ter um papel fundamental para o desenvolvimento local por proporcionar: (1) inclusão socioprodutiva dos agricultores (Van Der Ploeg et al., 2000); (2); fortalecimento de cadeias curtas de comercialização, de circuitos regionais e de redes agroalimentares alternativas (Maluf, 2004; Schneider \& Gazolla, 2017); e (3) construção de uma possível alternativa ao sistema agroalimentar hegemônico (Goodman, 2017; Conterato et al., 2011).

As feiras proporcionam a inclusão comercial dos agricultores familiares ao representar o final do processo de produção e o início do processo de comercialização (Godoy, 2005). É na feira que campo e cidade dialogam e que agricultores mantêm uma interface com o mundo urbano. Porém, nas feiras não estão presentes apenas agricultores familiares. A diversidade de agentes leva a diferentes análises tanto no que se refere à produção quanto à comercialização (Godoy, 2005; García-Barquero, 2016; Maluf, 2004; Ribeiro et al., 2003; Cabana \& Ichikawa, 2017; Pierri, 2010; Model \& Denardin, 2014).

As feiras também podem proporcionar o fortalecimento de cadeias curtas de comercialização, de circuitos regionais e de redes agroalimentares alternativas. Alguns autores definiram as cadeias curtas (short food supply chains) da seguinte forma: (1) venda direta "cara a cara", onde a confiança está na relação interpessoal; (2) "proximidade espacial", incluindo o que é produzido e distribuído em uma região reconhecida pelos consumidores; e (3) "espacialmente estendido", nesse caso, a confiança é transmitida por um processo de garantia da qualidade (certificação) (Renting et al., 2003; Darolt et al., 2016). Apesar das grandes diferenças entre os mercados, nota-se que a participação da sociedade civil na promoção de um novo olhar sobre o desenvolvimento rural é fundamental para a reprodução de cadeias curtas de comercialização (Renting et al., 2017).

Alguns estudos analisam as cadeias curtas de alimentos orgânicos sob a ótica da aproximação entre agricultor e consumidor por meio da confiança, lealdade e trocas de informações (Dias et al., 2017). Essa aproximação é um fator decisivo para que as iniciativas baseadas em canais curtos não se transformem em nichos elitizados de mercado e não sejam cooptadas por grandes grupos do sistema agroalimentar. Há exemplos no Reino Unido e nos Estados Unidos, onde redes agroalimentares alternativas se tornaram uma faceta diferenciada do sistema agroalimentar (Goodman, 2017).

Finalmente, as feiras também podem funcionar como espaço de economias populares baseadas na maximização do bem-estar de produtores e de consumidores, proporcionando uma alternativa ao sistema agroalimentar hegemônico (Hespanha et al., 2009). Segundo a Organização Internacional do Trabalho (OIT), atividades do setor informal se caracterizam pela pequena escala, pela baixa distinção entre capital e trabalho e pelas relações de trabalho pessoais (Hespanha et al., 2009). Ou seja, as feiras são eventos comerciais, que também se destacam como espaços de socialização e um exemplo secular de economia popular (Cabana \& Ichikawa, 2017). Como exemplo de mercados diretos, as feiras podem representar uma alternativa aos sistemas agroalimentares integrados (Wilkinson, 2003; Maluf, 2004). A 
inserção de agricultores de base familiar em mercados alternativos pode "constituir espaço de resistência e (re)construção de autonomia" (Conterato et al., 2011, p. 70).

Esses estudos, em geral qualitativos, exploraram o potencial de inserção comercial de agricultores familiares em canais curtos de comercialização. Não obstante, observa-se uma escassez de trabalhos acadêmicos que avaliam quantitativamente a abrangência desses canais alternativos para a inserção comercial dos agricultores familiares. Este trabalho apresenta uma contribuição adicional aos estudos qualitativos ao quantificar a participação de agricultores familiares nas feiras municipais do produtor.

A maior parte dos estudos sobre cadeias curtas no Brasil é realizada nos estados da região Sul, porém esse tipo de mercado existe em todo o país. O estado de Goiás é marcadamente conhecido pela relevância política e econômica da grande produção de commodities, o que atrai os olhares dos estudiosos das grandes cadeias agropecuárias. Assim, esse estudo contribui na medida em que revela a existência de cadeias curtas de comercialização com participação de agricultores familiares mesmo em um estado com cadeias longas consolidadas. Em Goiás, mais de $60 \%$ dos estabelecimentos agropecuários são de agricultores familiares, porém os estabelecimentos familiares ocupam pouco menos de $15 \%$ da área total dos estabelecimentos agropecuários e sua participação no valor total da produção é de 10,50\% (Instituto Brasileiro de Geografia e Estatística, 2017). Isso mostra que tal categoria é relevante tanto na dimensão social quanto na produtiva.

Neste estudo, realizado entre os meses de dezembro de 2017 e novembro de 2018, verifica-se em que medida as feiras do estado de Goiás representam alternativas de desenvolvimento rural ao proporcionar: (a) inclusão socioprodutiva de agricultores familiares; (b) fortalecimento de canais curtos de comercialização, circuitos regionais de produção e consumo e redes agroalimentares alternativas; e (c) uma possível alternativa ao modelo hegemônico do sistema agroalimentar industrial. Especificamente, buscam-se:

1. Verificar a proporção das feiras que representam uma alternativa de inserção comercial aos agricultores familiares; e

2. Identificar as características fundamentais das feiras que representam alternativas de inserção comercial para agricultores familiares.

\section{FUNDAMENTAÇÃO TEÓRICA}

A Nova Sociologia Econômica é uma recente e heterogênea expressão das Ciências Sociais construída em torno do conceito de embededdness, que tem sido traduzido como enraizamento, imbricamento e/ou imersão social, política e cultural (Niederle, 2016). A partir dos clássicos da Sociologia Econômica (Polanyi, 1957; Granovetter, 1985, por exemplo) e do esforço de estudiosos da Nova Sociologia Econômica, surge o conceito de embededdnes como peça fundamental para analisar a interação entre o econômico e o social. Embeddedness é uma característica clara das economias pré-capitalistas e em transição, mas também das economias capitalistas atuais e pode ser definido como a influência das redes e dos laços sociais nas interações econômicas, conferindo um caráter de reciprocidade, confiança e vantagem comparativa aos mercados diretos (Hinrichs, 2000).

Porém, para se relacionar tal conceito às feiras, faz-se necessário lançar mão de outros dois conceitos-chave que qualificam o termo embededdness: instrumentalismo e marketness (Hinrichs, 2000). Pode-se caracterizar marketness como uma forma de atuação no mercado em que os agentes priorizam os melhores preços, e instrumentalismo como um tipo de atuação que prioriza metas econômicas (Hinrichs, 2000). Ou seja, marketness está ligado à supremacia do preço e o instrumentalismo à supremacia da vantagem individual, sendo que o alto instrumentalismo prioriza as metas econômicas e o baixo instrumentalismo prioriza os laços sociais (Hinrichs, 2000).

Mas como o marketness e o instrumentalismo podem qualificar a análise do embededdness se, em princípio, são formas antagônicas de comportamento dos agentes no mercado? A noção de embededdness não é o contrário da noção de mercado (Hinrichs, 2000). É fundamental entender que as relações mercantis estão inseridas em contextos sociais (Plein \& Filippi, 2011), mas as relações sociais também estão inseridas em contextos econômicos. 
Dessa maneira, tanto agricultores quanto consumidores possuem traços de instrumentalismo e de marketness dentro de um canal de comercialização com alta embededdness que é a feira (Hinrichs, 2000).

Analisar os processos de produção, de distribuição e de consumo de alimentos apenas sob a ótica do consumidor consciente, do agricultor engajado e bem formado tecnicamente e das instituições (formais e não formais) fortes e democráticas não é suficiente para entender a diversidade de realidades em que produtores e consumidores estão inseridos. Esse tipo de perspectiva tem se mostrado ineficiente quando se tem o objetivo de entender os mercados e também de promover a justiça social nas relações de produção e consumo alternativas (Goodman, 2017).

A participação dos agricultores familiares nos canais de comercialização hegemônicos característicos dos circuitos longos (integrações, cadeias de commodities, mercados futuros e contratos com grandes redes varejistas) está cada vez mais condicionada a um tipo de produção e de gestão pouco acessíveis à agropecuária de base familiar (Wilkinson, 2003). Tais canais demandam um progressivo aumento de escala, especialização produtiva e suas transações ocorrem em ambiente com grande impessoalidade, o que limita a diversificação produtiva, a geração de produtos com qualidades regionalmente reconhecidas e a capacidade de reter ganhos econômicos nas localidades (Renting et al., 2003).

Constata-se assim o potencial de inclusão comercial de agricultores familiares pela comercialização em canais mais adequados às suas especificidades (Maluf, 2004). Além disso, a população urbana mudou sua postura frente ao consumo, demonstrando maior preocupação com a qualidade e com a origem do produto que chega à sua mesa, e maior interesse em conhecer os processos de produção pelos quais os alimentos passaram (Goodman, 2017). Assim, iniciam-se estudos que buscam compreender em que medida as cadeias curtas de abastecimento de alimentos contribuem para o desenvolvimento rural (Renting et al., 2003; Van Der Ploeg et al., 2000).

As cadeias curtas podem ser definidas em duas dimensões: a da definição de qualidade dos produtos (locais, regionais, tradicionais e orgânico, agroecológico, saudável) e a da estrutura organizacional da comercialização (venda direta, proximidade espacial e espacialmente estendida) (Renting et al., 2003). As feiras se inserem na categoria de venda direta em que as indicações de procedência e os atributos de qualidade se estabelecem na relação direta entre agricultor e consumidor (Renting et al., 2003). Apesar de importante desenvolvimento teórico recente, nota-se uma escassez de estudos quantitativos sobre a abrangência desses canais alternativos para a inserção comercial dos agricultores familiares.

Assim, ancorado nas referências supracitadas, o presente trabalho se insere no debate sobre as cadeias curtas e redes agroalimentares alternativas por meio da investigação sobre as feiras do estado de Goiás. Metodologicamente busca-se não se alinhar às análises supersocializada e subsocializada, e admite-se que os comportamentos instrumentalismo, marketness e embededdness se fazem presentes no canal de comercialização em estudo. Mesmo que esses comportamentos estejam presentes nas feiras, a literatura demonstra que esse canal de comercialização não pode ser analisado somente pela lente que investiga o processo de troca de produtos, bem como também não pode ser analisado somente pela lente que investiga as relações sociais.

Aqui, cabe ressaltar que essas modalidades de estudos são recorrentes na Europa, na América do Norte e na região Sul do Brasil, porém na região Centro-Oeste não existem muitos estudos sobre os mercados alternativos em que agricultores familiares participam. Dessa forma, o presente estudo se mostra relevante, já que as feiras compõem de maneira marcante o cotidiano econômico popular dos municípios goianos. Estudar as feiras de Goiás na perspectiva da inclusão dos agricultores familiares, tomando por base os conceitos da Sociologia Econômica e buscando criar critérios que situem as feiras de acordo com os indicadores de cadeias curtas e redes agroalimentares alternativas, pode contribuir com o avanço dos estudos sobre a relevância dos mercados alternativos. 


\section{METODOLOGIA}

A pesquisa foi realizada no estado de Goiás dada a importância das feiras municipais no estado. No Centro-Oeste brasileiro existem 85,8 feiras para cada milhão de habitantes, enquanto que as regiões Sudeste e Sul apresentam, respectivamente, 51,3 e 42,9 e Nordeste e Norte apresentam, respectivamente, 33,1 e 18,8 feiras para cada milhão de habitantes (Ministério do Desenvolvimento Social, 2014). Em Goiás, 88\% dos municípios possuem feiras funcionando regularmente, sendo que $41,92 \%$ das bancas são de agricultores familiares, $67,16 \%$ das feiras contam com a participação significativa desse tipo de agricultor e 30 municípios goianos possuem feiras exclusivas de agricultores familiares (Verano \& Medina, 2019). Porém, ainda são raros os estudos feitos na região Centro-Oeste sobre a inserção comercial de agricultores familiares em canais alternativos de comércio quando comparado com o número de estudos feitos nas regiões Sul e Sudeste.

O presente estudo teve como ponto de partida uma pesquisa anterior realizada entre os meses de março e novembro de 2017. O levantamento das feiras foi feito a partir de ligações telefônicas para os 246 municípios do estado de Goiás. Informações foram disponibilizadas por entrevistados em 201 municípios sobre as 369 feiras semanais existentes nesses municípios (Verano \& Medina, 2019). Foram retiradas do universo as 21 feiras que não tinham participação de agricultores familiares. Utilizando uma margem de erro de $10 \%$ e um grau de confiança de $90 \%$, obteve-se uma amostra de 59 feiras. Caso a margem de erro fosse de $5 \%$ e o grau de confiança de $95 \%$, a quantidade de feiras a serem investigadas seria de 189 , um número de feiras substancialmente grande para serem pesquisadas com os recursos financeiros disponíveis e dentro do prazo estabelecido pelo projeto de pesquisa. Assim, as generalizações devem ser feitas com cautela.

A amostragem foi feita da seguinte maneira: (a) escolheu-se aleatoriamente uma feira da lista de 369 feiras; (b) foi feita a entrevista por telefone com informantes-chave em cada município; (c) nos casos em que o respondente não conseguiu responder as perguntas mais complexas, descartou-se a entrevista e procedeu-se nova escolha aleatória; (d) as feiras em que o respondente não atendeu às ligações ou que não demonstrou abertura para a pesquisa foram descartadas; (e) chegou-se a um total de 68 entrevistas realizadas, porém nove estavam incompletas e foram descartadas. As nove entrevistas foram descartadas porque apresentaram um padrão recorrente de incompletude. Os respondentes dessas entrevistas conseguiam responder apenas as questões mais simples. A partir do momento em que as questões se tornaram mais complexas, tais entrevistados não conseguiram respondê-las, o que demonstrou que o respondente não estava apto a participar da pesquisa. Portanto, essas entrevistas foram canceladas.

A escolha dos informantes foi referendada por agentes ligados ao poder público local e a organizações de agricultores familiares. Por meio de ligações aos sindicatos, cooperativas e prefeituras, foi sendo identificado o respondente ideal para cada município. Assim, define-se esse entrevistado como informante-chave, pois são "indivíduos bem informados, ou seja, pessoas com amplos contatos e envolvimento ativo na comunidade, ou pessoas que têm um conhecimento especial, informação profunda e ampla sobre um sistema, serviço ou outro assunto de interesse específico do pesquisador" (Schensul, 2004 apud Bisol, 2012, p. 722). Inicialmente, foi feito contato com as prefeituras e se solicitou o contato da pessoa responsável pela feira. A partir de conversa preliminar com essa pessoa, foi decidido conjuntamente se o informante-chave seria o próprio responsável ou se seria algum outro agente (feirante pioneiro, liderança da agricultura familiar local ou da feira, agente do poder público, entre outros).

Foram formuladas perguntas com o objetivo de aferir variáveis que expressam em que medida as feiras do estado de Goiás representam alternativas de desenvolvimento para os agricultores familiares ao proporcionar: (a) inclusão socioprodutiva de agricultores familiares; (b) fortalecimento de canais curtos de comercialização, circuitos regionais de produção e consumo e redes agroalimentares alternativas; e (c) construção de uma possível alternativa ao sistema agroalimentar hegemônico. Todas as respostas foram codificadas de modo que, ao final, obteve-se uma planilha composta exclusivamente por números. 
Em seguida, as respostas foram dispostas de acordo com as variáveis referentes a cada critério e, para cada variável ou conjunto de variáveis, foi estabelecido um ponto de corte, dando origem a um indicador (Quadro 1). A determinação do ponto de corte levou em consideração observações empíricas anteriores à presente pesquisa, bem como interpretações dos autores acerca da relação entre a literatura científica disponível e o objeto de estudo. Não foram encontrados estudos que proponham indicadores que possam aferir cadeias curtas, redes agroalimentares alternativas, circuitos regionais, inclusão socioprodutiva da agricultura familiar e possibilidade alternativa ao modelo agroalimentar hegemônico. Por isso, foram utilizados diferentes trabalhos como subsídio para a definição das variáveis adotadas. Cabe ressaltar que não se pretende nesse estudo refutar ou confirmar a hipótese de que as feiras sejam um canal de comercialização capaz de conduzir uma mudança sistêmica no modelo agroalimentar hegemônico. As variáveis referentes ao critério "construção de uma possível alternativa ao sistema agroalimentar hegemônico" foram selecionadas no intuito de mensurar o protagonismo dos agricultores familiares nesse canal, a relevância da feira na reprodução econômica dos agricultores familiares e a ocorrência de práticas socioeconômicas características dos canais curtos e pouco comuns nos canais longos de comercialização.

Quadro 1. Resumo das variáveis levantadas, das referências teóricas que as sustentam e dos pontos de corte adotados para a definição de indicadores de atendimento aos critérios definidos

\begin{tabular}{|c|c|c|c|c|}
\hline Critério & Variáveis & Referencial teórico & Ponto de corte & Indicador \\
\hline \multirow[b]{2}{*}{$\begin{array}{c}\text { Inclusão } \\
\text { socioprodutiva dos } \\
\text { agricultores familiares }\end{array}$} & $\begin{array}{l}\text { Quantidades de bancas: (a) } \\
\text { total atualmente; (b) de } \\
\text { agricultores familiares; (c) de } \\
\text { agricultores familiares há } \\
\text { cinco anos; e (d) total há } \\
\text { cinco anos }\end{array}$ & Van Der Ploeg et al. (2000) & $\begin{array}{l}\text { Participação de agricultores } \\
\text { familiares maior ou igual a } \\
80 \% \text { ou em crescimento nos } \\
\text { últimos cinco anos }\end{array}$ & 1 \\
\hline & $\begin{array}{l}\text { Quantidade de bancas de } \\
\text { agricultores familiares que } \\
\text { vendem: (a) produtos in } \\
\text { natura; (b) produtos } \\
\text { processados; (c) produtos } \\
\text { com selo; (d) artesanato; e } \\
\text { (e) produtos da } \\
\text { sociobiodiversidade }\end{array}$ & $\begin{array}{l}\text { Potrich et al. (2017, p. 212- } \\
\text { 213); Wanderley (2003, } \\
\text { p. 50) }\end{array}$ & $\begin{array}{l}\text { Presença de produtos } \\
\text { in natura ou processados } \\
\text { em mais de } 75 \% \text { das bancas } \\
\text { da agricultura familiar e } \\
\text { ocorrência de agricultores } \\
\text { familiares expondo, no } \\
\text { mínimo, dois dos seguintes } \\
\text { produtos: (a) artesanato, (b) } \\
\text { certificados, (c) processados, } \\
\text { e (d) sociobiodiversidade }\end{array}$ & 2 \\
\hline \multirow{3}{*}{$\begin{array}{l}\text { Fortalecimento de } \\
\text { canais curtos de } \\
\text { comercialização, de } \\
\text { circuitos regionais de } \\
\text { produção e consumo } \\
\text { e de redes } \\
\text { agroalimentares } \\
\text { alternativas }\end{array}$} & $\begin{array}{l}\text { Quantidade de } \\
\text { atravessadores que expõem } \\
\text { na feira; quantidade de } \\
\text { atravessadores que expõem } \\
\text { na feira que compram } \\
\text { também da agricultura } \\
\text { familiar do município e } \\
\text { entorno }\end{array}$ & $\begin{array}{l}\text { Darolt et al. (2016, p. 6); } \\
\text { Faulim \& Azevedo (2003) }\end{array}$ & $\begin{array}{l}\text { Quantidade de } \\
\text { atravessadores menor que } \\
\text { a de agricultores familiares } \\
\text { e, entre as feiras em que } \\
\text { existem atravessadores, } \\
\text { pelo menos metade deles } \\
\text { adquire também da } \\
\text { agricultura familiar local }\end{array}$ & 3 \\
\hline & $\begin{array}{l}\text { Produtos específicos da } \\
\text { região (receitas antigas, } \\
\text { produtos típicos); fidelização } \\
\text { de clientes com } \\
\text { determinados feirantes da } \\
\text { agricultura familiar; } \\
\text { fidelização de clientes à feira } \\
\text { como um todo; ocorrência } \\
\text { de negócios de compra e } \\
\text { venda de insumos e serviços } \\
\text { entre os feirantes }\end{array}$ & $\begin{array}{l}\text { Maluf (2004, p. 304-305); } \\
\text { Wilkinson (2003); Goodman } \\
\text { (2017); Renting et al. (2017); } \\
\text { Schneider \& Gazolla (2017) }\end{array}$ & $\begin{array}{l}\text { Presença de pelo menos } \\
\text { três das quatro } \\
\text { características a seguir: } \\
\text { presença de produtos } \\
\text { específicos; fidelização de } \\
\text { consumidores a } \\
\text { determinados feirantes } \\
\text { agricultores; fidelização de } \\
\text { consumidores à feira como } \\
\text { um todo; e prática de } \\
\text { negócios de compra e } \\
\text { venda de insumos e serviços } \\
\text { entre os feirantes }\end{array}$ & 4 \\
\hline & $\begin{array}{l}\text { Ocorrência dos seguintes } \\
\text { tipos de produtos } \\
\text { agroindustrializados: } \\
\text { derivados do leite, derivados } \\
\text { da mandioca, derivados da }\end{array}$ & $\begin{array}{l}\text { Wanderley (2003, p. 50); De } \\
\text { Nazareth \& Wanderley } \\
\text { (2014, p. 32-33); Maluf (2004, } \\
\text { p. 310-311); Silva et al. (2015) }\end{array}$ & $\begin{array}{l}\text { Presença de pelo menos } \\
\text { quatro tipos de produtos } \\
\text { processados da agricultura } \\
\text { familiar de origens } \\
\text { diferentes }\end{array}$ & 5 \\
\hline
\end{tabular}


Quadro 1. Continuação...

\begin{tabular}{|c|c|c|c|c|}
\hline Critério & Variáveis & Referencial teórico & Ponto de corte & Indicador \\
\hline & $\begin{array}{l}\text { cana, polpas, } \\
\text { compotas/conservas, } \\
\text { agroindustrializados do } \\
\text { cerrado e frutos } \\
\text { desidratados }\end{array}$ & & & \\
\hline & $\begin{array}{l}\text { A feira tem algum tipo de } \\
\text { influência na: (a) definição } \\
\text { da lista do PNAE; (b) criação } \\
\text { ou fortalecimento de } \\
\text { políticas públicas locais; (c) } \\
\text { estabelecimento de novos } \\
\text { negócios e transações entre } \\
\text { agentes AF; e (d) estímulo } \\
\text { para a inserção de novos } \\
\text { agentes nas cadeias }\end{array}$ & $\begin{array}{c}\text { Godoy (2005); Sposito \& } \\
\text { Abreu (2017); Scarabelot \& } \\
\text { Schneider (2013) }\end{array}$ & $\begin{array}{l}\text { Feira influencia de alguma } \\
\text { maneira pelo menos três } \\
\text { das quatro questões a } \\
\text { seguir: PNAE; criação ou } \\
\text { fortalecimento de política } \\
\text { pública local; } \\
\text { estabelecimento de novos } \\
\text { negócios entre os agente } \\
\text { ligados a agricultura familiar; } \\
\text { e estímulo para a inserção } \\
\text { de novos agentes nas } \\
\text { cadeias produtivas }\end{array}$ & 6 \\
\hline \multirow{3}{*}{$\begin{array}{c}\text { Construção de uma } \\
\text { possível alternativa ao } \\
\text { modelo hegemônico } \\
\text { do sistema } \\
\text { agroalimentar }\end{array}$} & $\begin{array}{l}\text { Entre os agricultores } \\
\text { familiares que } \\
\text { comercializam na feira, que } \\
\text { porcentagem da renda } \\
\text { produtiva (em média) vem: } \\
\text { (a) da feira; (b) de outros } \\
\text { canais curtos; e (c) de canais } \\
\text { longos }\end{array}$ & $\begin{array}{l}\text { Ribeiro et al. (2003); Klock } \\
\text { Filho et al. (2016) }\end{array}$ & $\begin{array}{l}\text { Média da renda produtiva } \\
\text { dos feirantes da agricultura } \\
\text { familiar ser } \\
\text { majoritariamente oriunda } \\
\text { dos canais curtos }\end{array}$ & 7 \\
\hline & $\begin{array}{c}\text { Entre os agricultores } \\
\text { familiares que } \\
\text { comercializam na feira, qual } \\
\text { porcentagem participa de } \\
\text { associação, cooperativa, } \\
\text { sindicato ou movimento } \\
\text { social }\end{array}$ & $\begin{array}{l}\text { Silva et al. (2015); Gaspari \& } \\
\text { Khatounian (2016, p. 256- } \\
\text { 257) }\end{array}$ & $\begin{array}{l}\text { Número de feirantes da } \\
\text { agricultura familiar ligados a } \\
\text { organizações sociais da } \\
\text { agricultura familiar ser } \\
\text { maior do que aqueles que } \\
\text { não têm ligação alguma }\end{array}$ & 8 \\
\hline & $\begin{array}{l}\text { É comum entre os feirantes } \\
\text { as seguintes práticas? (a) } \\
\text { troca de produtos; (b) } \\
\text { alteração de preços de } \\
\text { acordo com as alterações } \\
\text { dos preços dos } \\
\text { supermercados; e (c) } \\
\text { manter em sigilo técnicas de } \\
\text { manejo ou estratégias de } \\
\text { gestão }\end{array}$ & $\begin{array}{l}\text { Ribeiro et al. (2003); } \\
\text { Pra et al., (2016); Sabourin } \\
\text { (2013); Hinrichs (2000) }\end{array}$ & $\begin{array}{l}\text { Presença de pelo menos } \\
\text { duas das seguintes } \\
\text { características: prática de } \\
\text { troca de produtos entre os } \\
\text { feirantes, não alteração de } \\
\text { preços de produtos de } \\
\text { acordo com os } \\
\text { supermercados e não } \\
\text { manter em sigilo técnicas de } \\
\text { manejo ou estratégias de } \\
\text { gestão }\end{array}$ & 9 \\
\hline
\end{tabular}

Foi utilizada a estatística descritiva para aferir percentualmente o comportamento do conjunto de feiras em cada variável, bem como em cada indicador e em cada critério. Também foi utilizada estatística descritiva para analisar o comportamento do conjunto de feiras concomitantemente nos três critérios. Para se proceder a tais análises foi utilizado o programa Excel. No Quadro 2 são apresentadas as variáveis enumeradas.

Quadro 2. Variáveis utilizadas e codificação

\begin{tabular}{|c|c|c|}
\hline \multicolumn{1}{|c|}{ Variável } & 1 \\
\hline Porcentagem de bancas de agricultores familiares atualmente & 2 \\
\hline Existência de banca(s) de assentados da reforma agrária & 3 \\
\hline Porcentagem de bancas de agricultores familiares que expõem produtos da sociobiodiversidade & 4 \\
\hline Porcentagem de bancas de agricultores familiares que expõem produtos in natura & 5 \\
\hline Porcentagem de bancas de agricultores familiares que expõem produtos processados & 6 \\
\hline Percentagem de bancas de agricultores familiares que expõem artesanato & 7 & 8 \\
\hline Média percentual da renda produtiva (dentre os feirantes agricultores familiares) oriunda de outros canais curtos & 9 \\
\hline Porcentagem de feirantes agricultores familiares ligados a organizações & & \\
\hline
\end{tabular}


Quadro 2. Continuação...

\begin{tabular}{|c|c|}
\hline Variável & Código \\
\hline Ocorrência de troca de produtos entre os feirantes & 10 \\
\hline Ocorrência entre os feirantes da prática de alteração de preços conforme os supermercados & 11 \\
\hline Ocorrência entre os feirantes da prática de manter em sigilo técnicas de manejo e gestão & 12 \\
\hline Porcentagem de bancas de atravessadores & 13 \\
\hline Porcentagem de bancas de atravessadores que compram de agricultores familiares locais & 14 \\
\hline Nível de diversidade de produtos processados entre os agricultores familiares & 15 \\
\hline Ocorrência de produtos específicos da região na feira & 16 \\
\hline Ocorrência de clientes fidelizados a determinados feirantes & 17 \\
\hline Ocorrência da prática de negócios de insumos e serviços entre os feirantes & 18 \\
\hline Influência da feira na lista de produtos do PNAE ou nas articulações que envolvem o programa & 19 \\
\hline Influência da feira em políticas públicas locais & 20 \\
\hline Influência da feira no estabelecimento de novos negócios e transações entre os agentes envolvidos na agricultura familiar & 21 \\
\hline Influência da feira na inserção de novos agentes nas cadeias produtivas locais & 22 \\
\hline
\end{tabular}

A estatística inferencial foi utilizada para buscar possíveis correlações e/ou relações de causalidade entre as variáveis. Foi utilizado o programa SPSS para testar os modelos estatísticos. Foi utilizada a correlação de Spearman para analisar as 22 variáveis e verificar quais relações geravam sigma menor que 0,05 . As que apresentaram maior ocorrência de sigma menor que 0,05 foram utilizadas como ponto de partida para se proceder às regressões logísticas. Para se entender o comportamento da variável "porcentagem de bancas de agricultores familiares", foi feita uma regressão logística utilizando essa variável como dependente na sua forma binária, tomando como independentes as variáveis: (1) "porcentagem de bancas de atravessadores"; (2) "porcentagem de feirantes agricultores familiares ligados a organizações"; (3) "média percentual da renda produtiva (dentre os feirantes agricultores familiares) oriunda de outros canais curtos"; e (4) "média percentual da renda produtiva (dentre os feirantes agricultores familiares) oriunda da feira".

Foi feita outra regressão logística com o objetivo de identificar relação de causalidade adotando como variável dependente a "influência da feira na criação ou fortalecimento de políticas públicas" e como independentes as variáveis: (1) "influência da feira na inserção de novos agentes nas cadeias produtivas"; (2) "influência da feira no Programa Nacional de Alimentação Escolar - PNAE"; (3) "porcentagem de bancas da agricultura familiar que expõem produtos processados"; e (4) "ocorrência de negócios de insumos e serviços entre feirantes agricultores familiares".

\section{RESULTADOS}

\subsection{Quantificação das feiras que representam alternativa de inserção comercial para os agricultores familiares}

\subsubsection{Inclusão socioprodutiva da agricultura familiar}

Dentre as feiras estudadas há grande e crescente participação de agricultores familiares entre os feirantes. As 59 feiras amostradas apresentaram média de 59,54 bancas por feira, sendo que, em média, 37,71 bancas são de agricultores familiares, representando $63,33 \%$ do total (Tabela 1). Há cinco anos essa média era de 48,97 bancas no total e de 31,22 bancas de agricultores familiares, representando $63,76 \%$ do total. Ou seja, em cinco anos as feiras cresceram em quantidade de bancas em $21,59 \%$ e em quantidade de bancas da agricultura familiar em $20,78 \%$. Porém, a porcentagem de participação da agricultura familiar por feira diminuiu $0,42 \%$.

As feiras também funcionam como espaço de comercialização para assentados, com média de 4,95 bancas de assentados da reforma agrária por feira. Entre as bancas da agricultura familiar: $28,35 \%$ expõem produtos da sociobiodiversidade (baru, pequi, babaçu, cajuzinho do cerrado, cascas e ervas medicinais), representando média de 10,69 bancas por 
feira; $82,78 \%$ expõem produtos in natura (folhosas, legumes, frutas, grãos), representando média de 31,22 bancas por feira; 40,04\% expõem produtos processados (queijos, doces, conservas, farinhas, polpas etc.), representando média de 15,10 bancas por feira; e 6,52\% expõem artesanato, representando média de 2,46 bancas por feira. Produtos com selos (de orgânicos, por exemplo) só foram identificados em uma feira.

Tabela 1. Média, desvio padrão e erro padrão de cada variável do critério inclusão socioprodutiva da agricultura familiar (em bancas por feira)

\begin{tabular}{|c|c|c|c|}
\hline & Média & $\begin{array}{l}\text { Desvio } \\
\text { padrão }\end{array}$ & Erro padrão \\
\hline Quantidade total de bancas & 59,54 & 52,03 & 6,77 \\
\hline Quantidade de bancas de agricultores familiares & 37,71 & 41,72 & 5,43 \\
\hline$\%$ de bancas de agricultores familiares & 63,33 & 27,93 & 3,63 \\
\hline Quantidade de bancas de agricultores familiares há 5 anos & 31,22 & 46,95 & 6,11 \\
\hline Quantidade de bancas no total há 5 anos & 48,97 & 56,77 & 7,39 \\
\hline Quantidade de bancas da reforma agrária & 4,95 & 7,72 & 1,01 \\
\hline $\begin{array}{l}\text { Quantidade média de bancas que vendem produtos da } \\
\text { sociobiodiversidade }\end{array}$ & 10,69 & 17,33 & 2,26 \\
\hline $\begin{array}{l}\text { Quantidade média de bancas de agricultores familiares } \\
\text { que vendem produtos in natura }\end{array}$ & 31,22 & 36,30 & 4,73 \\
\hline $\begin{array}{l}\text { Quantidade de bancas de agricultores familiares que } \\
\text { vendem produtos processados }\end{array}$ & 15,10 & 21,48 & 2,80 \\
\hline $\begin{array}{l}\text { Quantidade de bancas de agricultores familiares que } \\
\text { vendem produtos com selo }\end{array}$ & 0,03 & 0,26 & 0,03 \\
\hline $\begin{array}{l}\text { Quantidade de bancas de agricultores familiares que } \\
\text { expõem artesanato }\end{array}$ & 2,46 & 6,67 & 0,87 \\
\hline
\end{tabular}

Fonte: dados primários.

Os indicadores revelam que em $61,02 \%$ das feiras existe a participação de, pelo menos, $80 \%$ de bancas da agricultura familiar ou número de bancas da agricultura familiar em crescimento nos últimos cinco anos (indicador 1). Em 62,71\% das feiras, a relação quantidade de bancas com produtos in natura ou produtos processados por quantidade de bancas da agricultura familiar foi maior que $75 \%$ e também são expostos pelo menos dois dos seguintes produtos: processados, sociobiodiversidade, selo e artesanato (indicador 2). Em 42,37\% das feiras goianas os dois indicadores supracitados são atendidos concomitantemente. Esse resultado revela que quase a metade das feiras goianas tem participação relevante dos agricultores familiares e funciona como espaço para a comercialização dos seus diferentes produtos.

\subsubsection{Fortalecimento de canais curtos de comercialização, de circuitos regionais de produção e consumo e de redes agroalimentares alternativas}

Foi registrado que $66 \%$ das feiras possuem a figura do atravessador, porém, em 61,53\% dessas feiras, existem atravessadores que compram também de agricultores familiares do município e entorno. Em média, as feiras goianas possuem 8,63 bancas de atravessadores e três bancas de atravessadores que compram seus produtos de agricultores familiares locais. Foram levantadas 19 feiras com a ocorrência de produtos específicos da região, o que representa $32,20 \%$ do total amostrado. Em $100 \%$ das entrevistas, os respondentes afirmaram ser recorrente a prática de clientes fiéis à feira, ou seja, toda semana visitam, seja para comprar de feirantes específicos, seja para consumir algum alimento pronto, seja para socializar com os outros consumidores e feirantes. Clientes fidelizados a determinados feirantes foram citados por $89,83 \%$ dos respondentes. Em $57,62 \%$ das 59 feiras estudadas, os feirantes fazem negócios de compra e venda de insumos e de serviços entre eles. 
Acerca da influência da feira no desenvolvimento local, foram obtidos os seguintes resultados: (a) 33,89\% dos respondentes afirmaram que a feira influencia de alguma maneira a forma como a prefeitura executa o PNAE; (b) 50,84\% afirmaram que a feira influencia na formulação ou no fortalecimento de políticas públicas locais; (c) 76,27\% afirmaram que a feira influencia o surgimento de novos negócios e transações entre os agentes envolvidos nas questões da agricultura familiar; e (d) 64,4\% afirmaram que a feira contribui para a entrada de novos agentes nas cadeias produtivas da região. Os resultados sobre fortalecimento de canais curtos de comercialização, de circuitos regionais de produção e consumo e de redes agroalimentares alternativas estão resumidos na Tabela 2.

Tabela 2. Média, desvio padrão e erro padrão das variáveis discretas sobre fortalecimento de canais curtos de comercialização, de circuitos regionais de produção e consumo e de redes agroalimentares alternativas

\begin{tabular}{cccc} 
Quantidade de atravessadores que expõem da feira & Média & $\begin{array}{c}\text { Desvio } \\
\text { padrão }\end{array}$ & $\begin{array}{c}\text { Erro } \\
\text { padrão }\end{array}$ \\
$\begin{array}{c}\text { Quantidade de atravessadores da feira que compram de } \\
\text { agricultores familiares locais }\end{array}$ & $\mathbf{8 , 6 3}$ & 18,45 & 2,40 \\
\hline
\end{tabular}

Fonte: dados primários.

Dos quatro indicadores utilizados para analisar o fortalecimento de canais curtos de comercialização, circuitos regionais de produção e consumo e redes agroalimentares alternativas, obtiveram-se os seguintes resultados: (a) $72,88 \%$ das feiras atendem ao indicador 3 (quantidade de atravessadores menor que a de agricultores familiares e, em feiras em que existem atravessadores, pelo menos metade deles deve adquirir também da agricultura familiar local); (b) 67,8\% das feiras atendem ao indicador 4 (presença de pelo menos três das quatro características a seguir: presença de produtos específicos; fidelização de consumidores a determinados feirantes agricultores; fidelização de consumidores a feira como um todo e prática de negócios de compra e venda de insumos e serviços entre os feirantes); (c) 91,53\% das feiras atendem ao indicador 5 (presença de pelo menos 4 tipos de produtos processados de origens diferentes); e (d) 54,24\% das feiras atendem ao indicador 6 (feira influencia de alguma maneira pelo menos três das quatro questões a seguir: PNAE; criação ou fortalecimento de política pública local; estabelecimento de novos negócios entre os agentes ligados à agricultura familiar; e estímulo para a inserção de novos agentes nas cadeias produtivas). Do total, $32,20 \%$ das feiras cumpriram com os quatro indicadores desse critério concomitantemente.

\subsubsection{Construção de possível alternativa ao modelo hegemônico do sistema agroalimentar}

Da renda produtiva dos agricultores familiares feirantes, 51,29\% são provenientes da feira, $27,75 \%$ de outros canais curtos e apenas $20,97 \%$ são obtidos em canais longos de comercialização. Ou seja, os circuitos regionais de comercialização representam 79,03\% da renda daqueles agricultores familiares que estão nas feiras. Com relação à participação dos agricultores familiares feirantes em organizações, tais como associações, cooperativas, sindicatos e movimentos sociais, 55,84\% participam e 44,16\% não.

$50,84 \%$ dos respondentes afirmaram que os feirantes costumam trocar produtos entre si, $25,42 \%$ afirmaram que os feirantes costumam alterar os preços dos produtos de acordo com as alterações dos supermercados locais e $20,33 \%$ relataram que os feirantes costumam manter em sigilo suas técnicas de venda e estratégias de gestão. A Tabela 3 apresenta os resultados das variáveis escalares para o critério construção de possível alternativa ao modelo hegemônico do sistema agroalimentar. 
Tabela 3. Média, desvio padrão e erro padrão das variáveis discretas do critério construção de possível alternativa ao modelo hegemônico do sistema agroalimentar

\begin{tabular}{cccc} 
& Média & Desvio padrão & Erro padrão \\
\% da renda vem da feira & 51,29 & 19,79 & 2,58 \\
\% da renda vem de outros canais curtos & 27,75 & 17,81 & 2,32 \\
\% da renda vem de canais longos & 20,97 & 21,11 & 2,75 \\
\% não participa de organizações da agricultura familiar & 55,84 & 39,88 & 5,19 \\
\hline
\end{tabular}

Fonte: dados primários.

Dos três indicadores definidos a partir das variáveis, verificou-se que: (a) 76,27\% das feiras atendem ao indicador 7 (média da renda produtiva dos feirantes ser majoritariamente oriunda dos canais curtos); (b) $47,46 \%$ das feiras atendem ao indicador 8 (número de feirantes ligados a organizações sociais da agricultura familiar ser maior do que aqueles que não têm ligação alguma); e (c) 79,66\% das feiras atendem ao indicador 9 (presença de pelo menos duas das seguintes características - prática de troca de produtos entre os feirantes, não alteração de preços de produtos de acordo com os supermercados e não manter em sigilo técnicas de manejo ou estratégias de gestão). Dessa maneira, chega-se a 35,59\% de feiras que atendem a todos os indicadores relacionados ao critério de construção de uma possível alternativa ao modelo hegemônico do sistema agroalimentar.

Do total, $10,17 \%$ das feiras amostradas atendem aos três critérios concomitantemente ao proporcionar: (a) inclusão socioprodutiva dos agricultores familiares; (b) fortalecimento de canais curtos de comercialização e de circuitos regionais; e (c) possível alternativa ao sistema agroalimentar industrial. Essas feiras representam alternativas à inserção comercial dos agricultores familiares de acordo com os critérios definidos (Quadro 1).

\subsection{Características fundamentais das feiras que representam alternativas de inserção comercial dos agricultores familiares}

A Tabela 4 é referente à correlação de Spearman e demonstra as relações não paramétricas entre as variáveis selecionadas para as inferências estatísticas. Assim, é possível verificar quais variáveis (que estão codificadas em números, conforme o Quadro 2) tiveram o menor sigma (destacadas em negrito) quando confrontadas umas com as outras. A partir da análise dessa tabela, foram selecionadas as variáveis utilizadas nas regressões dos próximos tópicos. Notou-se que, em algumas variáveis, a ocorrência de significância menor que 0,05 era maior. Por isso, adotaram-se estas variáveis como ponto de partida para se iniciar a modelagem para as regressões.

Tabela 4. Correlações entre as variáveis estudadas

\begin{tabular}{ccccccccccccccccccccccccc} 
sigma & $\mathbf{1}$ & $\mathbf{2}$ & $\mathbf{3}$ & $\mathbf{4}$ & $\mathbf{5}$ & $\mathbf{6}$ & $\mathbf{7}$ & $\mathbf{8}$ & $\mathbf{9}$ & $\mathbf{1 0}$ & $\mathbf{1 1}$ & $\mathbf{1 2}$ & $\mathbf{1 3}$ & $\mathbf{1 4}$ & $\mathbf{1 5}$ & $\mathbf{1 6}$ & $\mathbf{1 7}$ & $\mathbf{1 8}$ & $\mathbf{1 9}$ & $\mathbf{2 0}$ & $\mathbf{2 1}$ & $\mathbf{2 2}$ \\
\hline 1 &. & 0,729 & 0,344 & 0,409 & 0,533 & 0,096 & 0,444 & 0,514 & 0 & 0,123 & 0,691 & 0,621 & 0 & 0,017 & 0,145 & 0,321 & 0,794 & 0,306 & 0,231 & 0,493 & 0,316 & 0,422 \\
2 & 0,729 &. & 0,73 & 0,295 & 0,475 & 0,415 & 0,694 & 0,21 & 0,238 & 0,251 & 0,511 & 0,28 & 0,424 & 0,177 & 0,63 & 0,993 & 0,014 & 0,655 & 0,791 & 0,697 & 0,699 & 0,11 \\
3 & 0,344 & 0,73 &. & 0,181 & 0,996 & 0,698 & 0,431 & 0,401 & 0,116 & 0,128 & 0,003 & 0,602 & 0,891 & 0,053 & 0,332 & 0,911 & 0,022 & 0,231 & 0,175 & 0,439 & 0,372 & 0,008 \\
4 & 0,409 & 0,295 & 0,181 &. & 0,01 & 0,396 & 0,573 & 0,484 & 0,806 & 0,078 & 0,289 & 0,552 & 0,965 & 0,411 & 0,752 & 0,735 & 0,149 & 0,425 & 0,903 & 0,113 & 0,892 & 0,567 \\
5 & 0,533 & 0,475 & 0,996 & 0,01 &. & 0,059 & 0,227 & 0,482 & 0,95 & 0,053 & 0,218 & 0,15 & 0,269 & 0,281 & 0,13 & 0,435 & 0,038 & 0,59 & 0,046 & 0,07 & 0,04 & 0,094 \\
6 & 0,096 & 0,415 & 0,698 & 0,396 & 0,059 &. & 0,283 & 0,627 & 0,526 & 0,822 & 0,645 & 0,85 & 0,158 & 0,392 & 0,002 & 0,48 & 0,262 & 0,211 & 0,376 & 0,375 & 0 & 0,03 \\
7 & 0,444 & 0,694 & 0,431 & 0,573 & 0,227 & 0,283 &. & 0,011 & 0,087 & 0,099 & 0,365 & 0,072 & 0,375 & 0,393 & 0,067 & 0,576 & 0,182 & 0,307 & 0,678 & 0,88 & 0,749 & 0,277 \\
8 & 0,514 & 0,21 & 0,401 & 0,484 & 0,482 & 0,627 & 0,011 &. & 0,072 & 0,851 & 0,349 & 0,042 & 0,32 & 0,01 & 0,239 & 0,84 & 0,6 & 0,626 & 0,756 & 0,293 & 0,922 & 0,659 \\
9 & 0 & 0,238 & 0,116 & 0,806 & 0,95 & 0,526 & 0,087 & 0,072 &. & 0,238 & 0,222 & 0,147 & 0,003 & 0,524 & 0,629 & 0,207 & 0,657 & 0,148 & 0,61 & 0,818 & 0,333 & 0,559 \\
10 & 0,123 & 0,251 & 0,128 & 0,078 & 0,053 & 0,822 & 0,099 & 0,851 & 0,238 &. & 0,339 & 0,569 & 0,109 & 0,186 & 0,071 & 0,718 & 0,08 & 0,052 & 0,24 & 0,372 & 0,502 & 0,718 \\
11 & 0,691 & 0,511 & 0,003 & 0,289 & 0,218 & 0,645 & 0,365 & 0,349 & 0,222 & 0,339 &. & 0,489 & 0,805 & 0,149 & 0,326 & 0,171 & 0,15 & 0,028 & 0,502 & 0,12 & 0,32 & 0,022 \\
12 & 0,621 & 0,28 & 0,602 & 0,552 & 0,15 & 0,85 & 0,072 & 0,042 & 0,147 & 0,569 & 0,489 &. & 0,581 & 0,309 & 0,89 & 0,203 & 0,817 & 0,217 & 0,532 & 0,569 & 0,528 & 0,067 \\
13 & 0 & 0,424 & 0,891 & 0,965 & 0,269 & 0,158 & 0,375 & 0,32 & 0,003 & 0,109 & 0,805 & 0,581 &. & 0 & 0,761 & 0,388 & 0,939 & 0,272 & 0,827 & 0,748 & 0,608 & 0,786 \\
\hline
\end{tabular}


Tabela 4. Continuação...

\begin{tabular}{ccccccccccccccccccccccccccc} 
sigma & $\mathbf{1}$ & $\mathbf{2}$ & $\mathbf{3}$ & $\mathbf{4}$ & $\mathbf{5}$ & $\mathbf{6}$ & $\mathbf{7}$ & $\mathbf{8}$ & $\mathbf{9}$ & $\mathbf{1 0}$ & $\mathbf{1 1}$ & $\mathbf{1 2}$ & $\mathbf{1 3}$ & $\mathbf{1 4}$ & $\mathbf{1 5}$ & $\mathbf{1 6}$ & $\mathbf{1 7}$ & $\mathbf{1 8}$ & $\mathbf{1 9}$ & $\mathbf{2 0}$ & $\mathbf{2 1}$ & $\mathbf{2 2}$ & $\mathbf{1 0}$ \\
14 & 0,017 & 0,177 & 0,053 & 0,411 & 0,281 & 0,392 & 0,393 & 0,01 & 0,524 & 0,186 & 0,149 & 0,309 & 0 &. & 0,201 & 0,914 & 0,846 & 0,905 & 0,776 & 0,853 & 0,621 & 0,127 \\
15 & 0,145 & 0,63 & 0,332 & 0,752 & 0,13 & 0,002 & 0,067 & 0,239 & 0,629 & 0,071 & 0,326 & 0,89 & 0,761 & 0,201 &. & 0,874 & 0,004 & 0,13 & 0,006 & 0,001 & 0,001 & 0,004 \\
16 & 0,321 & 0,993 & 0,911 & 0,735 & 0,435 & 0,48 & 0,576 & 0,84 & 0,207 & 0,718 & 0,171 & 0,203 & 0,388 & 0,914 & 0,874 &. & 0,077 & 0,561 & 0,747 & 0,853 & 0,332 & 0,112 \\
17 & 0,794 & 0,014 & 0,022 & 0,149 & 0,038 & 0,262 & 0,182 & 0,6 & 0,657 & 0,08 & 0,15 & 0,817 & 0,939 & 0,846 & 0,004 & 0,077 &. & 0,211 & 0,066 & 0,008 & 0,009 & 0 \\
18 & 0,306 & 0,655 & 0,231 & 0,425 & 0,59 & 0,211 & 0,307 & 0,626 & 0,148 & 0,052 & 0,028 & 0,217 & 0,272 & 0,905 & 0,13 & 0,561 & 0,211 &. & 0,775 & 0,002 & 0,011 & 0,024 \\
19 & 0,231 & 0,791 & 0,175 & 0,903 & 0,046 & 0,376 & 0,678 & 0,756 & 0,61 & 0,24 & 0,502 & 0,532 & 0,827 & 0,776 & 0,006 & 0,747 & 0,066 & 0,775 &. & 0,007 & 0,002 & 0,018 \\
20 & 0,493 & 0,697 & 0,439 & 0,113 & 0,07 & 0,375 & 0,88 & 0,293 & 0,818 & 0,372 & 0,12 & 0,569 & 0,748 & 0,853 & 0,001 & 0,853 & 0,008 & 0,002 & 0,007 &. & 0 & 0 \\
21 & 0,316 & 0,699 & 0,372 & 0,892 & 0,04 & 0 & 0,749 & 0,922 & 0,333 & 0,502 & 0,32 & 0,528 & 0,608 & 0,621 & 0,001 & 0,332 & 0,009 & 0,011 & 0,002 & 0 &. & 0 \\
22 & 0,422 & 0,11 & 0,008 & 0,567 & 0,094 & 0,03 & 0,277 & 0,659 & 0,559 & 0,718 & 0,022 & 0,067 & 0,786 & 0,127 & 0,004 & 0,112 & 0 & 0,024 & 0,018 & 0 & 0 &. \\
\hline
\end{tabular}

4.2.1. Regressão logística 1 (variável dependente - porcentagem de bancas da agricultura familiar - binário)

Foi feito um modelo para se executar a regressão logística que se mostrou válido, dado que: $X^{2}(4)=21,485, p$ (significância) $<0,005$, conforme a Tabela 5 .

Tabela 5. Qui-quadrado e significância da regressão logística 1

\begin{tabular}{ccccc} 
& & Qui-quadrado & df & Sig. \\
Etapa 1 & Etapa & 21,485 & 6 &, 002 \\
& Bloco & 21,485 & 6 &, 002 \\
& Modelo & 21,485 & 6 &, 002 \\
\hline
\end{tabular}

A explicação da variância oscilou entre 30,5 (Cox \& Snell) e 42,3 (Nagelkerke), conforme Tabela 6 . As previsões do modelo apresentam $78 \%$ de acerto.

Tabela 6. Variância do modelo estatístico

\begin{tabular}{cccc} 
Etapa & Verossimilhança de log -2 & R quadrado Cox \& Snell & $\begin{array}{c}\text { R quadrado } \\
\text { Nagelkerke }\end{array}$ \\
\hline 1 & $54.077^{a}$ &, 305 &, 423 \\
\hline
\end{tabular}

Tomando a variável dependente "porcentagem de bancas de agricultores familiares" como binária, foi feita uma regressão logística com as variáveis independentes: (a) "porcentagem de bancas de atravessadores" - variável 13; (b) "porcentagem de feirantes agricultores familiares ligados a organizações" - variável 9; (c) "média percentual da renda produtiva (dentre os feirantes agricultores familiares) oriunda de outros canais curtos" variável 8; e (d) "média percentual da renda produtiva (dentre os feirantes agricultores familiares) oriunda da feira" - variável 7.

Assim, chegou-se a duas variáveis que apresentaram relação de causalidade com a variável dependente. A variável 13 com nível de significância igual a 0,017 e relação de causalidade inversa, e a variável 9 com nível de significância igual a 0,02 e relação de causalidade direta, vide Tabela 7. Os cálculos sugerem que tendem a contar com maior participação de agricultores familiares as feiras onde a participação de atravessadores é pouco relevante e o nível de organização dos feirantes em instituições como associações, cooperativas, sindicatos e movimentos sociais é grande. 
Tabela 7. Regressão logística entre variáveis selecionadas no teste de correlação

\begin{tabular}{ccccccc} 
Variável N & B & S.E. & Wald & df & Sig. & Exp(B) \\
13 &,- 057 &, 024 & 5,647 & 1 &, 017 &, 945 \\
9 &, 022 &, 010 & 5,425 & 1 &, 020 & 1,022 \\
7 &, 018 &, 019 &, 940 & 1 &, 332 & 1,018 \\
8 &, 030 &, 022 & 1,790 & 1 &, 181 & 1,030 \\
Constante &,- 877 & 1,595 &, 302 & 1 &, 582 &, 416 \\
\hline
\end{tabular}

\subsubsection{Regressão logística 2 (variável dependente - influência da feira na criação ou no fortalecimento de políticas públicas)}

A partir da correlação calculada anteriormente, percebeu-se que as variáveis referentes à influência da feira na rede agroalimentar local e a variável "ocorrência da prática de negócios de insumos e serviços entre os feirantes" são as que possuem maior possibilidade de possuir algum tipo de relação de causalidade. Isto posto, definiu-se que a variável "influência da feira em políticas públicas locais" seria a dependente e as outras seriam as independentes. Optouse por essa variável dependente, pois é importante identificar os motivos que levam uma feira a ter influência na formulação e no fortalecimento de ações voltadas à agricultura familiar e ao sistema agroalimentar local.

Foi feito um modelo para se executar a regressão logística que se mostrou válido dado que: $X^{2}(4)=24,715, p$ (significância) $<0,005$, conforme Tabela 8.

Tabela 8. Qui-quadrado e significância da regressão logística 2

\begin{tabular}{ccccc} 
& & Qui-quadrado & df & Sig. \\
Etapa 1 & Etapa & 24,715 & 4 &, 000 \\
& Bloco & 24,715 & 4 &, 000 \\
& Modelo & 24,715 & 4 &, 000 \\
\hline
\end{tabular}

A explicação da variância oscilou entre 34,2 (Cox \& Snell) e 45,6 (Nagelkerke), conforme Tabela 9. As previsões do modelo apresentam 79,7\% de acerto.

Tabela 9. Variância do modelo estatístico

\begin{tabular}{cccc} 
Etapa & Verossimilhança de log -2 & R quadrado Cox \& Snell & $\begin{array}{c}\text { R quadrado } \\
\text { Nagelkerke }\end{array}$ \\
\hline 1 & $57.060^{a}$ &, 342 &, 456 \\
\hline
\end{tabular}

A partir do indicativo obtido por meio da correlação, foi feita uma regressão logística para se verificar a relação de causalidade. Assim, chegou-se a três variáveis que apresentaram relação de causalidade com a variável dependente: (a) "ocorrência da prática de negócios de insumos e serviços entre os feirantes" - variável 18 (com nível de significância igual a 0,012); (b) "influência da feira na lista de produtos do PNAE ou nas articulações que envolvem o programa" - variável 19 (com nível de significância igual a 0,04); e (c) "influência da feira na inserção de novos agentes nas cadeias produtivas locais" - variável 22 (com nível de significância igual a 0,03), conforme Tabela 10. Percebe-se com isso que a feira pode contribuir para o fortalecimento ou criação de políticas públicas locais voltadas à agricultura 
familiar quando é catalisadora da articulação entre os diversos agentes do sistema agroalimentar local.

Tabela 10. Regressão logística entre variáveis selecionadas no teste de correlação

\begin{tabular}{ccccccc} 
Variável N & B & S.E. & Wald & df & Sig. & Exp(B) \\
\hline 18 & $-1,873$ &, 743 & 6,353 & 1 &, 012 &, 154 \\
19 & $-1,639$ &, 798 & 4,220 & 1 &, 040 &, 194 \\
22 & $-1,595$ &, 733 & 4,730 & 1 &, 030 &, 203 \\
Constante & 2,220 & 1,029 & 4,654 & 1 &, 031 & 9,210 \\
\hline
\end{tabular}

\section{DISCUSSÃO}

Os resultados revelaram que $10,17 \%$ das feiras de Goiás proporcionam a inclusão socioprodutiva dos agricultores familiares, o fortalecimento de canais curtos de comercialização e uma possível alternativa ao sistema agroindustrial. Ou seja, seis das 59 feiras estudadas atendem aos três critérios concomitantemente. Ao analisar os indicadores separadamente observa-se que mais de $50 \%$ das feiras atenderam a sete dos nove indicadores utilizados e todas as feiras atenderam ao menos dois indicadores.

Em menor ou maior escala, as feiras são um espaço importante para a inserção comercial de agricultores familiares. Considerando que as cadeias curtas de comercialização são espaços de imersão social com finalidade econômica (Hinrichs, 2000) e que a construção do novo paradigma de desenvolvimento rural pressupõe melhores rendimentos econômicos aos agricultores familiares (Van Der Ploeg et al., 2000), as feiras podem contribuir para a consolidação de um novo paradigma de desenvolvimento rural, pois são espaços, em grande medida, protagonizados por agricultores familiares locais onde a participação de organizações representativas dessa categoria e a dinamização da economia regional proporcionam movimentos de aproximação entre produtor e consumidor.

A grande ocorrência de produtos específicos das regiões, de clientes fidelizados (tanto a determinados feirantes quanto à feira como um todo) e de processos de trocas de experiências e de produtos entre os feirantes demonstra que as feiras estudadas são um tipo de mercado onde a dimensão social e a econômica se misturam, conferindo um caráter de reciprocidade e de fortalecimento de redes sociais. Essa constatação vai ao encontro do que Hinrichs (2000) discute quando aborda o conceito embededdness. O autor também destaca que é necessário analisar o caráter instrumentalism e o marketness nos mercados com características de embededdness. Os resultados revelaram que existem essas características nas feiras, pois os feirantes alteram preços dos produtos de acordo com oscilações do mercado, negociam produtos e serviços entre eles e com os clientes, e se organizam em associações e cooperativas, ou seja, os agricultores familiares participam da feira para fortalecer sua inserção social e construir redes territoriais, mas também para melhorar seus ganhos econômicos e qualificar sua produção.

Não obstante, este estudo de caráter quantitativo permite identificar as limitações da abrangência desse novo paradigma de desenvolvimento. Ao mesmo tempo em que os dados revelam a existência de feiras que proporcionam a inclusão socioprodutiva dos agricultores familiares, os resultados quantitativos também demonstram que parte importante das feiras não atende aos pressupostos desse novo paradigma descritos nas pesquisas qualitativas (Scarabelot \& Schneider, 2013; Van Der Ploeg et al., 2000). Parte dos agricultores não tem acesso a alternativas comerciais representadas pelo novo paradigma, tal como já identificado em outros estudos (Medina et al., 2015).

A análise inferencial identificou correlações lineares entre diversas variáveis, algumas delas com relação de causalidade. Tanto a regressão linear quanto a logística identificaram que a ocorrência de atravessadores interfere negativamente no protagonismo dos 
agricultores familiares. Em grande parte das feiras estudadas, coexistem cadeias curtas (agricultores feirantes) e cadeias longas (atravessadores feirantes). A presença de atravessadores minimiza o protagonismo da agricultura familiar e fragiliza o processo de encurtamento das cadeias produtivas. Essa afirmação corrobora os resultados obtidos por Feenstra (2002) que concluiu que o envolvimento direto e horizontal dos diversos agentes das redes comunitárias de alimentação é fundamental para o sucesso do canal alternativo de comercialização.

A análise inferencial, baseada na regressão logística, também demonstrou que o dinamismo e os desdobramentos resultantes da feira no âmbito do sistema agroalimentar local influenciam as políticas públicas locais. Ou seja, nas feiras onde ocorrem articulações para entrada de novos agentes nas cadeias produtivas, negociações de compra e venda de insumos e serviços entre agricultores familiares e organização da categoria para atuar no PNAE, o poder público tende a atuar no sentido de apoiar as comunidades do campo com suas demandas. Isso corrobora a afirmação de Scarabelot \& Schneider (2013) sobre a importância do envolvimento dos agentes do poder público e da sociedade civil para a consolidação de um sistema agroalimentar local.

Por fim, o presente estudo avançou no sentido de propor variáveis e indicadores que podem caracterizar as feiras no contexto de um novo paradigma de desenvolvimento rural. A partir da utilização de tais variáveis e indicadores a pesquisa científica sobre as feiras ganha uma nova ferramenta de investigação

\section{CONCLUSÕES}

Em Goiás, 42,37\% das feiras oferecem oportunidades de inclusão socioprodutiva aos agricultores familiares, $32,20 \%$ fortalecem canais curtos de comercialização, circuitos regionais de produção e consumo e redes agroalimentares alternativas e 35,59\% funcionam como possível alternativa ao sistema agroalimentar industrial. Do total, 10,17\% das feiras atendem aos três objetivos supracitados concomitantemente.

Demonstrou-se estatisticamente que: (1) quanto menor a porcentagem de atravessadores nas feiras e maior a de agricultores familiares ligados às organizações representativas, maior é a possibilidade de a feira ter mais bancas da agricultura familiar; (2) quanto maior a relevância da feira como espaço de articulação entre agentes e para a catalisação de novos negócios entre agricultores, maior a possibilidade de esse canal influenciar a criação ou o fortalecimento de políticas públicas.

O presente estudo contribui com trabalhos anteriores no sentido de propor variáveis e indicadores que podem caracterizar as feiras no contexto de um novo paradigma de desenvolvimento rural. A partir da utilização de tais variáveis, a pesquisa científica sobre as feiras ganha uma ferramenta de investigação de caráter quantitativo. Por ter se proposto a avançar na formulação de critérios que situem e quantifiquem as feiras no âmbito das cadeias curtas e redes agroalimentares alternativas, o presente estudo suscita discussões que podem resultar em aprimoramentos metodológicos futuros. Aspectos importantes a serem considerados são: (a) em que medida as variáveis designadas a cada critério explicam as variáveis dependentes em diferentes regiões do país? (b) em que medida os pontos de corte adotados para algumas variáveis podem ser aprimorados considerando outras realidades?; e (c) em que medida outras variáveis da complexidade sociológica dos mercados alternativos podem ser incorporadas em avaliações quantitativas? Trabalhos futuros podem adotar 0 modelo da presente pesquisa e verificar a validade para diferentes realidades, bem como sugerir alterações nas variáveis adotadas.

Algumas questões podem ser objeto de futuras pesquisas que visem aprofundar 0 conhecimento sobre a função e a relevância das feiras, tais como: (a) qual a importância do arranjo institucional do município ou do território na viabilização de um modelo de feira que atenda aos anseios de consumidores e de agricultores familiares e aos preceitos de um modelo de desenvolvimento rural inclusivo?; (b) como a feira exerce o papel de aproximação e articulação entre consumidores, agricultores, poder público e sociedade civil?; (c) em que medida o comportamento instrumentalista e o de mercado contribuem ou atrapalham a feira no âmbito das cadeias curtas de comercialização?, e (d) como as feiras podem contribuir para 
a consolidação de cadeias curtas em regiões empobrecidas, onde as figuras do consumidor consciente e do agricultor capacitado não são recorrentes?

\section{REFERÊNCIAS BIBLIOGRÁFICAS}

Bisol, C. A. (2012). Estratégias de pesquisa em contexto de diversidade cultural: entrevistas de listagem livre, entrevistas com informantes chave e grupos focais. Estudos de Psicologia, 29(Supl. 1), 719-726.

Cabana, R. D. P. L., \& Ichikawa, E. Y. (2017). As identidades fragmentadas no cotidiano da Feira do Produtor de Maringá. Organizações \& Sociedade, 24(81), 285-304.

Conterato, M. A., Niederle, P. A., Radomsky, G., \& Schneider, S. (2011). Mercantilização e mercados : a construção da diversidade da agricultura na ruralidade contemporânea. In S. Schneider \& M. Gazolla (Orgs.), Os atores do desenvo/vimento rural: perspectivas teóricas e práticas sociais (pp. 67-90). Porto Alegre: UFRGS.

Darolt, M. R., Lamine, C., Brandenburg, A., Alencar, M. D. C. F., \& Abreu, L. S. (2016). Redes alimentares e novas relações produção-consumo na França e no Brasil. Ambiente \& Sociedade, 19(2), 1-22.

De Nazareth, M., \& Wanderley, B. (2014). O Campesinato Brasileiro : uma história de resistência. Revista de Economia e Sociologia Rural, 52(1), S025-S044.

Dias, V. V., Révillion, J. P., \& Talamini, E. (2017). Cadeias curtas de alimentos orgânicos: aspectos das relações de proximidade entre consumidores e agricultores no Brasil. In M. Gazolla \& S. Schneider (Orgs.), Cadeias curtas e redes agroalimentares alternativas: negócios e mercados da agricultura familiar. Porto Alegre: UFRGS.

Faulim, E. J., \& Azevedo, P. F. (2003). Distribuição de hortaliças na agricultura familiar : uma analise das transações. Informações Econômicas, 33(11), 24-37.

Feenstra, G. (2002). Creating space for sustainable food systems: Lessons from de field. Agriculture and Human Values, 19, 99-106. http://dx.doi.org/10.1023/A:1016095421310

García-Barquero, M. E. (2016). Análisis del comportamiento de mercado en las ferias del agricultor de la Gran Área Metropolitana. Revista Tecnología en Marcha, 29(1), 83. http://dx.doi.org/10.18845/tm.v29i1.2541

Gaspari, L. C. D., \& Khatounian, C. A. (2016). Características das famílias, estruturação da produção e estratégias de comercialização em um assentamento de reforma agrária. Revista de Economia e Sociologia Rural, 54(2), 243-260.

Godoy, W. I. (2005). As feiras-livres de Pelotas, RS: estudo sobre a dimensão sócio-econômica de um sistema de comercialização (Tese de doutorado). Universidade Federal de Pelotas, Pelotas.

Goodman, D. (2017). Espaço e lugar nas redes alimentares alternativas: conectando produção e consumo. In: S. Schneider \& M. Gazolla (Orgs.), Cadeias curtas e redes agroalimentares alternativas negócios e mercados da agricultura familiar (p. 59-82, $1^{\text {a }}$ ed). Porto Alegre: Editora da UFRGS.

Granovetter, M. (1985). Economic Action and Social Structure: the problem of Embeddedness. American Journal of Sociology, 91(03), 481-510.

Hespanha, P., Hespanha, P., \& Namorado, R. (2009). Da expansão dos mercados à metamorfose das economias populares. Revista Critica de Ciencias Sociais, (84), 49-63.

Hinrichs, C. C. (2000). Embeddedness and local food systems: Notes on two types of direct agricultural market. Journal of Rural Studies, 16(3), 295-303.

Instituto Brasileiro de Geografia e Estatística - IBGE. (2017). Dados do Censo Agropecuário. Rio de Janeiro.

Klock Filho, L. P., Vasques, S. T., \& Godoy, W. I. (2016). Organizações sociais e canais de comercialização acessados por agricultores agroecológicos: um estudo de caso na feira-livre de Chapecó/SC. Colóquio Revista do Desenvolvimento Regional, 13(1), 109-121.

Maluf, R. S. (2004). Mercados agroalimentares e a agricultura familiar no Brasil : agregação de valor, cadeias integradas e circuitos regionais. Ensaios FEE, 25(1), 299-322.

Medina, G., Almeida, C., Novaes, E., Godar, J., \& Pokorni, B. (2015). Development conditions for family farming: lessons from Brazil. World Development, 74, 386-396. http://dx.doi.org/10.1016/j.worlddev.2015.05.023

Ministério do Desenvolvimento Social - MDS (2014). Mapeamento de segurança alimentar e nutricional nos estados e municípios: resultados preliminares. Brasília: MDS. 
Model, P. A., \& Denardin, V. F. (2014). Agricultura familiar e a formação de circuitos curtos de comercialização através das feiras livres: o caso da Matinfeira - Paraná. In Encontro Internacional sobre Gestão Empresarial e Meio Ambiente (pp. 1-15). São Paulo: FEA-USP.

Niederle, P. A. (2016). Mercados como arenas de luta por reconhecimento: disputas morais na construção dos dispositivos de qualificação dos alimentos. Política \& Sociedade, 15(33), 97-130.

Pierri, M. C. Q. M. (2010). Um recorte em território artificializado: agricultura familiar e comercialização na Feira dos Goianos - Gama/DF (Dissertação de mestrado). Universidade de Brasília, Brasília.

Plein, C., \& Filippi, E. E. (2011). Capitalismo, agricultura familiar e mercados. Redes, 16(3), 98-121.

Polanyi, K. (1957). Aristotle Discovers the Economy. In: K. Polanyi, C. Arensberg \& H. Pearson (Orgs.), Trade and Market in the Early Empires (p. 64-94). Glencoe, III: Free Press and Falcon's Wing Press.

Potrich, R., Grzybovski, D., \& Toebe, C. S. (2017). Sustentabilidade nas pequenas propriedades rurais : um estudo exploratório sobre a percepção do agricultor. Estudos Sociedade e Agricultura, 25(1), 208228.

Pra, M., Sabourin, E., Petersen, P., \& Silveira, L. (2016). Lógicas e estratégias de comercialização na agricultura familiar do Agreste da Paraíba. Estudos Sociedade e Agricultura, 24(1), 5-27.

Renting, H., Marsden, T. K., \& Banks, J. (2003). Understanding alternative food networks: exploring the role of short food supply chains in rural development. Environment \& Planning A, 35(3), 393-411.

Renting, H., Marsden, T. K., \& Banks, J. (2017). Compreendendo as redes alimentares alternativas: o papel das cadeias curtas de abastecimento de alimentos no desenvolvimento rural. In: S. Schneider \& M. Gazolla (Orgs.), Cadeias curtas e redes agroalimentares alternativas - negócios e mercados da agricultura familiar (pp. 27-52). Porto Alegre: Editora da UFRGS.

Ribeiro, E. M., Ângulo, J. L. G., Noronha, A. B., Castro, B. S., Galizoni, F. M., Calixto, J. S., \& Silvestre, L. H. (2003). A feira e o trabalho rural no Alto Jequitinhonha: um estudo de caso. Unimontes Científica, $5(1), 1-20$.

Sabourin, E. P. (2013). Comercialização dos produtos agrícolas e reciprocidade no Brasil. Estudos Sociedade e Agricultura, 21(1), 5-33.

Scarabelot, M., \& Schneider, S. (2013). As cadeias agroalimentares curtas e desenvolvimento local: um estudo de caso no município de Nova Veneza/Sc. Revista Faz Ciência, 14(19), 101.

Schneider, S., \& Gazolla, M. (2017). Cadeias curtas e redes agroalimentares alternativas. In: In: S. Schneider \& M. Gazolla (Orgs.), Cadeias curtas e redes agroalimentares alternativas - negócios e mercados da agricultura familiar ( $1^{\text {a }}$ ed). Porto Alegre: Editora da UFRGS.

Silva, G. P., Balem, T. A., Silveira, P. R. C., \& Bem, A. E. (2015). A constituição do SIAL (Sistema Agroalimentar Localizado) de São Francisco de Assis (RS) A partir de estratégias locais e políticas públicas. Organizações Rurais \& Agroindustriais, 17(3), 302-317.

Sposito, E. C., \& Abreu, L. S. (2017). Diversidade da produção familiar e da comercialização de produtos orgânicos de Vitória (ES). Redes, 22(3), 292-315.

Van Der Ploeg, J. D., Renting, H., Brunori, G., Knickel, K., Mannion, J., Marsden, T., de Roest, K., SevillaGuzman, E., \& Ventura, F. (2000). Rural development: from practices and policies towards theory rural development: from practices and policies towards theory. Sociologia Ruralis, 40(4), 391-408.

Verano, T., \& Medina, G. (2019). Comercialização por agricultores familiares em feiras municipais: quantificação, participação e localização no estado de Goiás. Interações, 20(4), 1045-1056.

Wanderley, M. D. N. B. (2003). Agricultura familiar e campesinato: rupturas e continuidade. Estudos Sociedade e Agricultura, 11(2), 20.

Wilkinson, J. (2003). A agricultura familiar ante o novo padrão de competitividade do sistema agroalimentar. Estudos Sociedade e Agricultura, 11(2), 62-87. 